\title{
Tuning $\mathrm{Pt}$ and $\mathrm{Cu}$ sites population inside functionalized UiO-67 MOF by controlling activation conditions
}

\author{
L. Braglia, ${ }^{a b}$ E. Borfecchia, (D) a K. A. Lomachenko, ${ }^{b c}$ A. L. Bugaev, ${ }^{a b}$

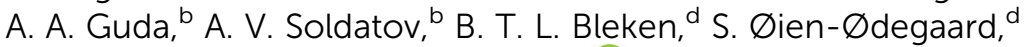 \\ U. Olsbye, ${ }^{d}$ K. P. Lillerud, ${ }^{d}$ S. Bordiga, (D) ad G. Agostini, ${ }^{\text {ce }}$ M. Manzoli (D) ${ }^{f}$ \\ and C. Lamberti (iD *bg
}

Received 18th January 2017, Accepted 6th February 2017

DOI: $10.1039 / c 7 f d 00024 c$

The exceptional thermal and chemical stability of the UiO-66, -67 and -68 classes of isostructural MOFs [J. Am. Chem. Soc., 2008, 130, 13850] makes them ideal materials for functionalization purposes aimed at introducing active centres for potential application in heterogeneous catalysis. We previously demonstrated that a small fraction (up to $10 \%$ ) of the linkers in the UiO-67 MOF can be replaced by bipyridinedicarboxylate (bpydc) moieties exhibiting metal-chelating ability and enabling the grafting of $\mathrm{Pt}(\mathrm{II})$ and $\mathrm{Pt}(\mathrm{IV})$ ions in the MOF framework [Chem. Mater., 2015, 27, 1042] upon interaction with $\mathrm{PtCl}_{2}$ or $\mathrm{PtCl}_{4}$ precursors. Herein we extend this functionalization approach in two directions. First, we show that by controlling the activation of the UiO-67-Pt we can move from a material hosting isolated $\mathrm{Pt}\left({ }_{1}\right)$ sites anchored to the MOF framework with $\mathrm{Pt}(\Perp)$ exhibiting two coordination vacancies (potentially interesting for $\mathrm{C}-\mathrm{H}$ bond activation) to the formation of very small $\mathrm{Pt}$ nanoparticles hosted inside the MOF cavities (potentially interesting for hydrogenation reactions). The second direction consists of the extension of the approach to the insertion of $\mathrm{Cu}(I)$, obtained via interaction with $\mathrm{CuCl}_{2}$, and exhibiting interesting redox properties. All materials have been characterized by in situ $\mathrm{X}$-ray absorption spectroscopy at the $\mathrm{Pt}_{3^{-}}$and $\mathrm{Cu} \mathrm{K}$-edges.

\footnotetext{
${ }^{a}$ Department of Chemistry, NIS Interdepartmental Centre and INSRM Reference Centre, University of Turin, via Quarello 15A, I-10135 Turin, Italy

${ }^{b} I R C$ "Smart Materials", Southern Federal University, Zorge Street 5, 344090 Rostov-on-Don, Russia ${ }^{c}$ European Synchrotron Radiation Facility, 71 avenue des Martyrs, CS 40220, 38043 Grenoble Cedex 9, France 'inGAP Centre for Research Based Innovation, Department of Chemistry, University of Oslo, Oslo, Norway ${ }^{e}$ Leibniz Institute for Catalysis at the University of Rostock (LIKAT), Albert-Einstein-Str. 29A, D-18059 Rostock, Germany

${ }^{f}$ Department of Drug Science and Technology, NIS Interdepartmental Centre, University of Torino, Via P. Giuria 9, 10125 Torino, Italy

${ }^{g}$ Department of Chemistry, CrisDi Interdepartmental Centre and INSRM Reference, University of Turin, via Pietro Giuria 7, 10125 Turin, Italy. E-mail: carlo.lamberti@unito.it
} 
Metal-organic frameworks (MOFs) are crystalline, porous solids consisting of metal ions or clusters, coordinated with organic molecules. The large number of combinations for inorganic and organic building units offers an almost infinite variety of structural solutions with a wide range of properties. ${ }^{1-7}$ An additional degree of freedom is the functionalization of the MOFs that further extends the range of possibly obtainable structures. ${ }^{8-14}$ For about one decade, MOFs have been considered as potential candidates for shape-selective heterogeneous catalysis for reactions running at mild conditions. ${ }^{15-24}$

As the metal sites in the cornerstones of most of the MOF structures show a maximum of one coordination vacancy (see e.g. the HKUST-1 (ref. 25-27) and the CPO-27, or MOF-74, ${ }^{28-31}$ cases), non-functionalized MOFs have limited application in catalysis, where at least two coordination vacancies are required in the active site. Consequently, functionalization represents an attractive way to introduce active sites in MOF structures.

The recently discovered UiO-66, -67 and -68 classes of iso-structural MOFs are obtained by connecting $\mathrm{Zr}_{6} \mathrm{O}_{4}(\mathrm{OH})_{4}$ inorganic cornerstones with 1,4-benzenedicarboxylate (bdc), 4,4'-biphenyl-dicarboxylate (bpdc) or 4,4'-terphenyldicarboxylate (tpdc) linkers, for the UiO-66, UiO-67 and UiO-68 MOFs, respectively. ${ }^{32-34}$ Due to their outstanding stability at high temperatures, high pressures and in the presence of different solvents, these materials are among the few MOFs already commercialized for potential applications in the fields of catalysis, gas storage, and gas purification. For the same reasons the UiO-66, -67 and -68 family has already been subjected to several functionalization procedures, involving both the $\mathrm{Zr}_{6} \mathrm{O}_{4}(\mathrm{OH})_{4}$ inorganic cornerstone and the organic linkers, as well as intentionally toned defect insertion. ${ }^{35-38}$ As far as the inorganic cornerstone functionalization is concerned, $\mathrm{Zr}$ atoms have been partially or totally substituted with $\mathrm{Hf}^{39,40}$ or $\mathrm{Ce}^{41-44}$ atoms. Substitution with cerium allows alteration of the $\mathrm{Ce}(\mathrm{IV}) \leftrightarrow \mathrm{Ce}(\mathrm{III})$ redox chemistry, providing some reactivity to the cornerstone. Coming to the linker functionalization, several routes have been undertaken, including: (i) grafting of $-\mathrm{NH}_{2},-\mathrm{NO}_{2},-\mathrm{Br}$ groups $\sigma$-bonded to the bdc ring; ${ }^{45-49}$ grafting of $\mathrm{Cr}(\mathrm{CO})_{3}$ complexes $\pi$-bonded to the bdc ring; ${ }^{50}$ (iii) encapsulation of $\mathrm{Pt},{ }^{51,52} \mathrm{Pd},{ }^{53,54} \mathrm{Au},{ }^{55} \mathrm{AuPd},{ }^{56} \mathrm{Ru},{ }^{57} \mathrm{Ag},{ }^{58}$ or metal nanoparticles (NPs) inside the tetrahedral and octahedral MOF cavities. Moreover, for UiO-67, the substitution of a small fraction of bpdc linkers by bipyridine-dicarboxylate (bpydc) moieties, exhibiting metal-chelating ability, enables the path for post-synthetic grafting of metal ions in the MOF framework upon interaction with metal precursors. ${ }^{51,59,60}$

Herein we extend this functionalization approach into two directions. First, by tuning the $\mathrm{H}_{2}$ flow during the activation procedure of the UiO-67-Pt we can move from a material hosting isolated framework Pt(II) exhibiting two coordination vacancies (potentially interesting for $\mathrm{C}-\mathrm{H}$ bond activation) to the formation of very small Pt NPs hosted inside the MOF cavities (potentially interesting for hydrogenation reactions). The second direction consists of the extension of the approach to the insertion of $\mathrm{Cu}$ (II), obtained via interaction with $\mathrm{CuCl}_{2}$, leading to interesting redox properties already evidenced in other Cu-containing MOFs. ${ }^{61-63}$

The fact that MOFs are mainly constituted by low $\mathrm{Z}$ elements $(\mathrm{C}, \mathrm{O}, \mathrm{N}, \mathrm{H})$ implies that they are almost transparent to hard $\mathrm{X}$-rays; ${ }^{\mathbf{6 4 , 6 5}}$ this allows the 
collection of high quality transmission X-ray absorption spectra at the metal K- or L-edges, characterized by an optimized edge jump $\Delta \mu \mathrm{x}$ as high as 1.0-1.5, resulting in accurate data, analyzable up to $15-20 \AA^{-1}$ (vide infra Fig. 3a). This makes X-ray absorption techniques both in the extended X-ray absorption fine structure (EXAFS) and X-ray absorption near edge structure (XANES) regions a technique of choice in characterizing the electronic and structural configuration of metal centers hosted in MOF structures, as testified by many previous studies. $^{28,29,32-34,40,48,59,64,66-90}$ In this study we have characterized Pt- and $\mathrm{Cu}$ functionalized UiO-67 MOFs via in situ X-ray absorption spectroscopy at the Pt $\mathrm{L}_{3^{-}}$and $\mathrm{Cu}$ K-edges, respectively.

\section{Experimental and methods}

\subsection{Materials}

All chemicals were used as received. $\mathrm{ZrCl}_{4}$ (Sigma) must be dry and of high purity for successful synthesis.

2.1.1. Synthesis of $2,2^{\prime}$-bipyridine-5, $5^{\prime}$-dicarboxylic acid. In a $25 \mathrm{~mL}$ beaker glass, $6.0 \mathrm{~g} \mathrm{HNO}_{3(\mathrm{aq})}(65 \%)$ was slowly added to $9.0 \mathrm{~mL}$ deionized water to obtain $26 \mathrm{wt} \% \mathrm{HNO}_{3} .1 .50 \mathrm{~g}$ 5,5'-dimethyl-2,2'-bipyridine was added and quickly dissolved in the acid. The solution was transferred to a $25 \mathrm{~mL}$ Teflon-lined autoclave which was heated to $160{ }^{\circ} \mathrm{C}$ and kept at that temperature for 16 hours. The autoclave was allowed to slowly cool to room temperature before opening. A crystalline, weakly yellow powder was isolated by filtration and then washed 5 times with approximately $50 \mathrm{~mL}$ portions of water. The filtrate was cooled to $273 \mathrm{~K}$ and carefully brought to $\mathrm{pH} 7$ by addition of saturated $\mathrm{NaHCO}_{3}$ solution, at which a weakly yellow precipitate was formed. This solid was isolated by filtration and washed in the same manner as above. ${ }^{1} \mathrm{H}$-NMR confirmed that the two solids were both pure $\mathrm{H}_{2}$ bpydc. The yield was $1.74 \mathrm{~g}$ (92\%).

Crystals of $\mathrm{H}_{2}$ bpydc suitable for single crystal XRD were obtained directly from the autoclave. A complete data set was acquired on a Bruker D8 Venture equipped with a Photon 100 detector, using Mo K $\alpha$ radiation $(\lambda=0.71073 \AA)$. Data reduction was performed with the Bruker Apex3 Suite, the structure was solved with ShelxT ${ }^{91}$ and refined with ShelxL..$^{92}$ Olex2 was used as the user interface..$^{93}$ The $\mathrm{H}_{2}$ bpydc molecules form 1D $\mathrm{H}$-bonded chains analogous to the previously reported structure, ${ }^{94}$ but the packing mode is slightly different.

2.1.2. Synthesis of UiO-67-bpy $\left(\mathrm{PtCl}_{2}\right)$ by postsynthetic modification. $116 \mu \mathrm{L}$ (6.5 mmol) $\mathrm{H}_{2} \mathrm{O}, 502 \mathrm{mg}(2.15 \mathrm{mmol}) \mathrm{ZrCl}_{4}$ and $2.63 \mathrm{~g}(21.5 \mathrm{mmol})$ benzoic acid was added to $50 \mathrm{~mL}$ of DMF in a beaker glass, and the mixture was stirred until a clear solution was obtained. It was then heated to $393 \mathrm{~K}$ while stirring gently. $469 \mathrm{mg}$ (1.94 mmol) $\mathrm{H}_{2}$ bpdc and $110 \mathrm{mg}(0.22 \mathrm{mmol}) \mathrm{H}_{2}$ bpydc was then added, and a clear solution was quickly obtained. The solution was transferred to a round-bottom flask and kept at $393 \mathrm{~K}$ for 72 hours while stirring in a reflux apparatus. A colorless powder was isolated by filtration, and then immediately suspended in $20 \mathrm{~mL}$ fresh DMF while still wet. The suspension was kept at $373 \mathrm{~K}$ while stirring to extract unreacted precursor and modulator from the pores. The powder was isolated by filtration, washed twice with $15 \mathrm{~mL}$ portions of hot DMF $(373 \mathrm{~K}), 5$ times with $30 \mathrm{~mL}$ portions of dry acetone, and then dried in air at 423 K. 
The material, $1000 \mathrm{mg}$, was submerged in a solution of $112 \mathrm{mg} \mathrm{K} \mathrm{K}_{2} \mathrm{PtCl}_{4}$ in 20 $\mathrm{mL}$ DMF and kept at $373 \mathrm{~K}$ for 24 hours while stirring. A bright yellow powder was isolated by filtration, washed twice with $50 \mathrm{~mL}$ portions of hot DMF (373 K), 2 times with $50 \mathrm{~mL}$ portions of dry acetone, and then dried in air at $423 \mathrm{~K}$.

2.1.3. Synthesis of UiO-67-bpy(CuOHCl) by postsynthetic modification. The starting UiO-67-bpy MOFs were synthesized by a standard solvothermal method, as described in more detail in previous studies, ${ }^{59}$ by reacting $\mathrm{ZrCl}_{4}$ with different mixtures of $\mathrm{H}_{2}$ bpdc and $\mathrm{H}_{2}$ bpydc linkers ( $10 \mathrm{wt} \%$ of bpydc) in a solution of dimethylformamide (DMF). 5 molar equivalents of benzoic acid were added to obtain a modulator effect, which resulted in a porous MOF with monodispersed particles and well-defined crystallinity. ${ }^{95}$ The $\mathrm{Cu}-$ functionalized $\mathrm{Cu}$-UiO-67-bpy derivatives were prepared employing a post synthesis modification approach, by submerging the MOF powder in solutions of $\mathrm{CuCl}_{2}$ dihydrate in 2-propanol, and heating the solution at reflux conditions for one hour. The resulting bright green powders were washed in three cycles with 2-propanol.

\subsection{Pt $\mathrm{L}_{3^{-}}$and $\mathrm{Cu}$ K-edge XAS data collections, EXAFS data analysis}

$\mathrm{Pt} \mathrm{L}_{3}$-edge (11 $560 \mathrm{eV}$ ) and Cu K-edge (8980 eV) XAS data were collected at the I811 beamline of the Max Lab II source (Lund, Sweden). ${ }^{96}$ Max Lab II was operated at 1.5 GeV with a uniform current between 250 and $100 \mathrm{~mA}$. The white beam produced by a liquid He-cooled superconducting wiggler was monochromatized by a horizontally sagittally focused double-crystal $\mathrm{Si}(111)$ monochromator. At the $\mathrm{Cu}$ K-edge the monochromator was detuned to $20 \%$ to minimize the third

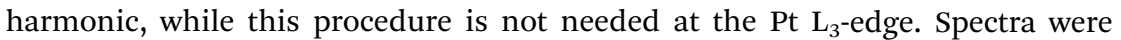
collected in transmission mode using $30 \mathrm{~cm}$ ionization chambers for $I_{0}$ and $I_{1}$; the intensity $I_{2}$ transmitted by a Pt (or $\mathrm{Cu}$ ) reference foil located after the sample was measured using a photodiode, and the resulting spectrum was employed for energy alignment purposes.

All XAS spectra were measured employing a home-made cell allowing sample activation in temperature and gas dosage under in situ or operando conditions, ${ }^{97}$ monitoring the evolution of the XAS features while controlling the temperature and gas feed. The XAS data reduction and EXAFS extraction procedure was performed using the Athena codes. ${ }^{98}$ The parametric EXAFS data analysis was performed with IFEFFIT ${ }^{99}$ code that employs phases and amplitudes computed by FEFF6 code, ${ }^{100,101}$ as detailed elsewhere. ${ }^{59}$

\subsection{Pt $\mathbf{L}_{3}$-edge XANES simulations}

For all clusters simulating the local environments of $\mathrm{Pt}$ atoms hosted inside the UiO-67-Pt MOF and successive modification by chemical reactivity with $\mathrm{H}_{2}, \mathrm{Br}_{2}$ and toluene-3,4-dithiol $\left(\mathrm{H}_{2} \mathrm{tdt}\right)$, the ground-state electronic structures and atomic geometries were calculated using the hybrid DFT B3LYP level of theory ${ }^{\mathbf{1 0 2}}$ using the ADF-2015 program package. ${ }^{\mathbf{1 0 3 , 1 0 4}}$ The QZ4P basis set was used in all calculations. Thus, each atomic orbital was represented as a combination of four Slater type orbitals with different exponential powers and four polarization functions. We first obtain eigenvalues and corresponding wave functions. The matrix elements are then evaluated for transitions between the $2 \mathrm{p}$ core level and unoccupied MOs using dipole transition operators. In order to compare with 
experimental XANES spectra, a convolution of calculated matrix elements was performed with a Lorentzian profile using the energy-dependent line width. In the pre-edge region, the width of the Lorentzian profile corresponds to a core hole lifetime broadening for Pt. This value is then increased in higher energy intervals with a smooth arctangent function. The parameters of the matrix element calculations (grid step, size number of unoccupied MOs) and energy convolution are fixed once for all complexes. The calculated spectra were subsequently aligned according to the energy value of the Pt $2 \mathrm{p}$ orbital, thus reproducing the chemical shift for different species. A rigid shift with the identical value was applied for all spectra in order to align the energy scale between experimental data and theoretical calculations.

\section{Results and discussion}

\subsection{Pt-functionalization of UiO-67 MOF: state of the art}

Introducing a chemically active Pt site as part of the UiO-67 framework is of great interest as platinum has rich redox chemistry, showing 0, II and IV stable oxidation states. Moreover, certain square planar Pt(II) coordination complexes are known to be active in $\mathrm{C}-\mathrm{H}$ bond activation, ${ }^{\mathbf{1 0 5}}$ for example see the scheme reported in Fig. $1 \mathrm{~b}$ and c. In particular, dichlorobipyrimidyl platinum(II), $\mathrm{PtCl}_{2}$ (BPYM), performs the catalytic oxidation in fuming or concentrated sulfuric acid, achieving high yields of methanol with selectivity higher than $90 \% .{ }^{\mathbf{1 0 6 , 1 0 7}}$ It is consequently of potential interest to investigate the possibility to heterogenize such a process anchoring the active Pt(II) complex on some high surface area material such as that recently shown by the group of Schüth, for polymers first $^{108,109}$ and for $\mathrm{N}$-doped carbons ${ }^{\mathbf{1 1 0}}$ successively, or as done more recently by Øien et al. ${ }^{59}$ who have succeeded in functionalizing UiO-67 with $\left(\mathrm{H}_{2}\right.$ bpydc) $\mathrm{PtCl}_{2}$ or $\left(\mathrm{H}_{2}\right.$ bpydc $) \mathrm{PtCl}_{4}$ units, substituting $10 \%$ of the standard bpdc linkers. The authors used EXAFS, XANES and valence-to-core resonant inelastic X-ray scattering

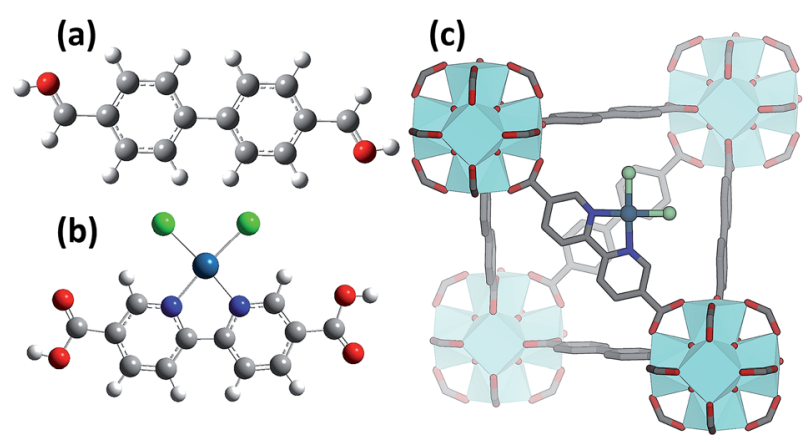

Fig. 1 Part (a): structure of the standard bpydc linker used for the synthesis of the nonfunctionalised UiO-67 MOF. Part (b): structure of the $\left(\mathrm{H}_{2}\right.$ bpydc) $\mathrm{PtCl}_{2}$ linker inserted in the $\mathrm{UiO}-67$ structure showing $2 \mathrm{~N}$ and $2 \mathrm{Cl}$ in the first coordination shell of $\mathrm{Pt}(॥)$ and showing the distortion induced on the two rings by N/C substitution and Pt insertion. Part (c): threedimensional representation of the Pt(II)-functionalized UiO-67 MOF. Colour code: $\mathrm{H}$ white, C grey, N blue, O red, Cl green, Pt cyan. Previously unpublished figure. 
techniques to prove the insertion of Pt atoms in the expected framework position of UiO-67 (see Fig. 1c).

Using EXAFS and XANES, the local coordination environment and the oxidation state of Pt can be monitored under in situ conditions. The elimination of chloride ligands from $\mathrm{Pt}$ in a continuous gas flow of diluted $\mathrm{H}_{2}\left(3 \% \mathrm{H}_{2}\right.$ in $\left.\mathrm{He}\right)$ have been monitored by EXAFS during temperature ramping (Fig. 2a). The spectrum collected at room temperature (black curve) exhibits both the first shell Pt-N and the Pt-Cl contributions centred around 1.5 and $1.9 \AA$ in the phase uncorrected Fourier transform (FT), highlighted by vertical blue and green dashed lines, respectively. Upon increasing the temperature, both contributions decrease in intensity because of the increased Debye-Waller factors $\left({\sigma_{\mathrm{N}}}^{2}\right.$ and ${\sigma_{\mathrm{Cl}}}^{2})$. Starting from about $600 \mathrm{~K}$ the Pt-Cl contribution shows a much more relevant decrease in temperature than the $\mathrm{Pt}-\mathrm{N}$ contribution, suggesting that the system starts losing chlorine ligands. A standard EXAFS analysis failed because of the high correlation between the coordination numbers $\left(N_{\mathrm{Pt}-\mathrm{N}} ; N_{\mathrm{Pt}-\mathrm{Cl}}\right)$ and the thermal parameters $\left({\sigma_{\mathrm{N}}}^{2} ;{\sigma_{\mathrm{Cl}}}^{2}\right) .{ }^{59}$ The problem was solved by applying an advanced data analysis approach briefly summarized hereafter.

First, we worked only on the sub-set of data in the interval between RT and $473 \mathrm{~K}$. In this temperature range no bond breaking occurs, so it was possible to fix $N_{\mathrm{N}}=N_{\mathrm{Cl}}=2$. On that sub-set of in situ EXAFS data a parametric refinement was performed, commonly employed in XRPD Rietveld refinements, ${ }^{111,112}$ adopting the Einstein model to describe the temperature dependence of both ${\sigma_{\mathrm{N}}}^{2}$ and ${\sigma_{\mathrm{Cl}}}^{2}$ factors. The Einstein model approximates the vibrational density of states as a Dirac delta function spiked at a single frequency named the Einstein frequency $\left(\omega_{\mathrm{E}}\right)$. The model assumes that the $\mathrm{Pt}-\mathrm{N}$ pairs (or $\mathrm{Pt}-\mathrm{Cl}$ ) behave as a quantum harmonic oscillator of mass equal to the reduced mass of the atomic pair ( $M=13.070$ and 30.004 amu for the Pt-N and Pt-Cl pairs, respectively). Under such assumptions, the $\sigma^{2}(T)$ behaviour is straightforwardly determined by the only $\omega_{\mathrm{E}}$ parameter according to eqn (1)::59,113
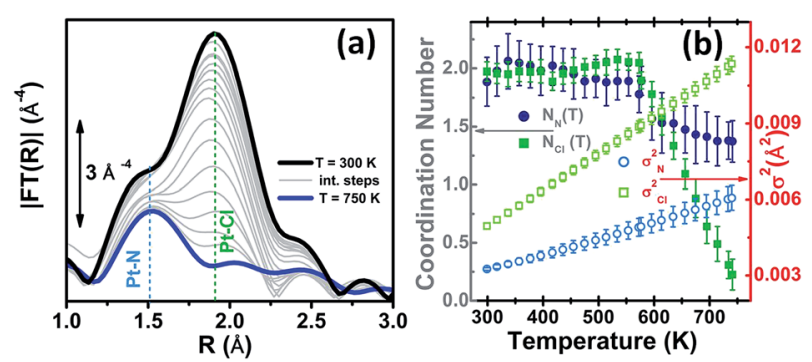

Fig. 2 Part (a): $k^{3}$-weighted, phase uncorrected FT of $\mathrm{Pt}_{\mathrm{L}_{3}}$-edge EXAFS spectra collected during the in situ $\mathrm{H}_{2}$-TPR experiments on the $\mathrm{PtCl}_{2}\left(\mathrm{H}_{2}\right.$ bpydc) functionalized UiO-67-Pt(I) MOF in the $300 \mathrm{~K}$ (black spectrum) $-750 \mathrm{~K}$ (blue spectrum) range performed with diluted $\mathrm{H}_{2}$ flow ( $3 \% \mathrm{H}_{2}$ in $\mathrm{He}$ ). Part (b): quantitative data analysis of the set of spectra shown in part (a) by modelling the temperature dependence of the Debye-Waller factors $\left(\sigma_{\mathrm{N}}{ }^{2}\right.$ and $\left.\sigma_{C l}{ }^{2}\right)$ based on the Einstein model. Previously unpublished figure replotting data published in ref. 59 . 


$$
\sigma^{2}(T)=\frac{\hbar}{M \omega_{\mathrm{E}}} \cot h\left[\frac{\hbar \omega_{\mathrm{E}}}{2 k_{\mathrm{B}} T}\right]=\frac{\hbar^{2}}{M k_{\mathrm{B}} \Theta_{\mathrm{E}}} \cot h\left[\frac{\Theta_{\mathrm{E}}}{2 T}\right] \text {. }
$$

$\Theta_{\mathrm{E}}$ is the Einstein temperature of the Pt-N (or Pt-Cl) bond, related to the Einstein frequency by the relationship: $\hbar \omega_{\mathrm{E}}=k_{\mathrm{B}} \Theta_{\mathrm{E}}$, where $\hbar=1.055 \times 10^{-34} \mathrm{~J} \mathrm{~s}$ is the reduced Planck constant and $k_{\mathrm{B}}=1.38 \times 10^{-23} \mathrm{~J} \mathrm{~K}^{-1}$ is the Boltzmann constant.

This approach allowed us to reduce the number of parameters used to optimize the thermal factors of the series from $\sim 40$ to only two, $\Theta_{\mathrm{E}}(\mathrm{Pt}-\mathrm{N})$ and $\Theta_{\mathrm{E}}(\mathrm{Pt}-$ $\mathrm{Cl}$ ), with a consequent reduction of the correlation among the optimized parameters and thus a reduction of the relative error bars. Once the Einstein temperatures $\Theta_{\mathrm{E}}(\mathrm{Pt}-\mathrm{N})=(709 \pm 63) \mathrm{K}$ and $\Theta_{\mathrm{E}}(\mathrm{Pt}-\mathrm{Cl})=(333 \pm 9) \mathrm{K}$ were obtained, the dependence of both ${\sigma_{\mathrm{N}}}^{2}$ and $\sigma_{\mathrm{Cl}}^{2} v s$. T was straightforwardly obtained via eqn (1) and extrapolated on the whole set of data (i.e. also above $473 \mathrm{~K}$ ). This strategy allowed stable fits in the whole temperature range while optimizing both $N_{\mathrm{N}}$ and $N_{\mathrm{Cl}}$, as shown in Fig. $2 \mathrm{~b}$. From this data analysis, it is evident that both $N_{\mathrm{N}}$ and $N_{\mathrm{Cl}}$ are stable to the stoichiometric values of 2.0 up to $575 \mathrm{~K}$, when they start to decrease together. However, while $N_{\mathrm{Cl}}$ decreases almost linearly to 0.4 at $750 \mathrm{~K}, N_{\mathrm{N}}$ undergoes a fast decrease to 1.6 at $610 \mathrm{~K}$ and then remains almost stable, with a value at $750 \mathrm{~K}$ of 1.4. This means that a prolonged activation in diluted $\mathrm{H}_{2}$ of the UiO-67-Pt(II) MOF in the 610-640 K interval will result in a minimal loss of Pt-sites, which will lose the $\mathrm{Pt}-\mathrm{N}$ connection with the framework, but break of an important fraction of the Pt-Cl bonds. The experiment reported in Fig. 2 proved that this activation temperature interval is ideal to obtain a material where most of the Pt species are still linked to the MOF framework, exhibiting the coordination vacancies needed to make the UiO-67-Pt(II) material a potential heterogeneous catalyst. ${ }^{59}$ The presence of coordination vacancies at platinum sites was also directly testified by IR spectroscopy of adsorbed CO. No evidence of a Pt-Pt signal of an aggregated platinum phase was observed in the experiment reported in Fig. 2.

EXAFS was also used to prove the high reactivity of the Pt(II) species hosted in the UiO-67 MOF. We followed the liquid-phase ligand exchange with toluene-3,4dithiol ( $\mathrm{H}_{2} \mathrm{tdt}$ ) and the liquid-phase oxidative addition of $\mathrm{Br}_{2}$ to $\mathrm{Pt}$ (see Fig. 3). All the observed reactions take place without any degradation of the framework, as testified by parallel XRPD experiments.

Also the XANES part of the XAS spectrum is sensitive to the changes undergone by the local environment of $\mathrm{Pt}(\mathrm{II})$ along the chemical reactions reported in Fig. 3. Upon a change in the Pt oxidation state, the Pt $\mathrm{L}_{3}$-edge XANES will show a very small edge shift while it will exhibit a noticeable variation of the intensity of the "white-line" peak. ${ }^{59,114-116}$ Indeed, the XANES part of the Pt $\mathrm{L}_{3}$-edge mainly derives from the promotion of core $2 p_{3 / 2}$ electrons into empty $5 d_{3 / 2}, 5 d_{5 / 2}$ and 6 s valence states, so mainly probing the unoccupied density of 5 d-states and partially $6 \mathrm{~s}-$ states. The XANES spectra reported in Fig. 4a for the UiO-67-Pt(II) MOF before (red line) and after interaction with $\mathrm{H}_{2}$ tdt (blue line) and $\mathrm{Br}_{2}$ (green line) clearly follow this phenomenological trend. In particular, interaction with $\mathrm{H}_{2}$ tdt (blue spectrum in Fig. 4a) does not affect the white line intensity, affecting only the post edge and EXAFS region of the spectrum; on this basis it was concluded that a ligand exchange reaction occurs where two $\mathrm{Cl}$ ligands are exchanged with the 

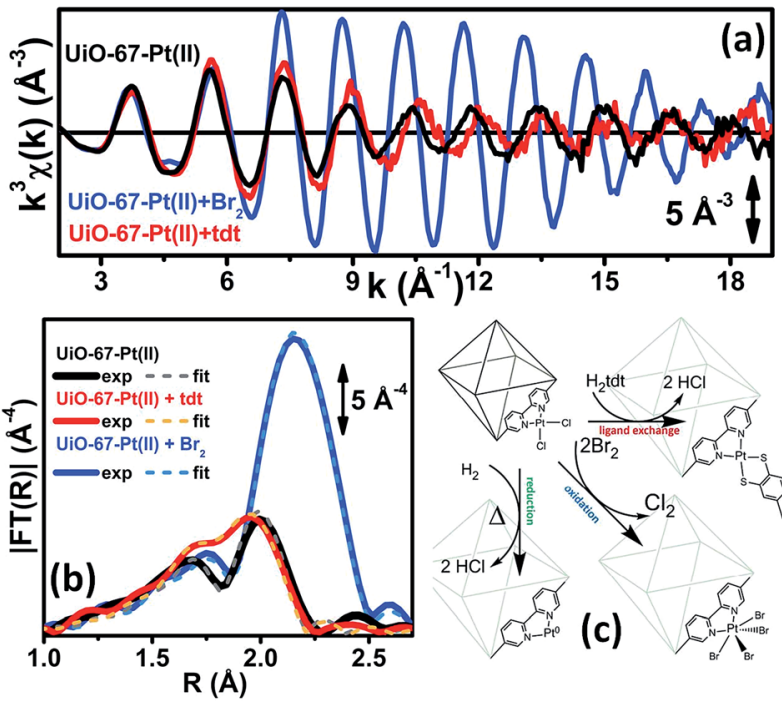

Fig. 3 Part (a): experimental Pt $\mathrm{L}_{3}$-edge $k^{3} \chi(k)$ spectra of UiO-67-Pt(॥) before (black line) and after interaction with $\mathrm{H}_{2}$ tdt (red line) and $\mathrm{Br}_{2}$ (blue line). Part (b): modulus of the $k^{3}$-weighted, phase uncorrected FT of the experimental EXAFS spectra reported in part (a), solid lines, same color code as in part (a). The corresponding best fits are also reported, as dashed lines of similar colour. Part (c): schematic representation of the reactivity of Pt(॥) species in functionalized UiO-67-Pt MOFs that has been highlighted in the EXAFS study reported in Fig. 2 and in parts ( $a$ and b) of this figure. The sketched square bi-pyramid represents the octahedral large cavity of UiO-67, measuring about $16 \AA$ in diagonal. ${ }^{32,34}$ Previously unpublished figure replotting data published in ref. 59.

two $\mathrm{S}$ atoms of the bulky $\mathrm{H}_{2}$ tdt unit. Conversely, interaction with $\mathrm{Br}_{2}$ (green spectrum in Fig. 4a) results in a significant increase in the white line intensity, testifying an oxidation process from $\mathrm{Pt}(\mathrm{II})$ to $\mathrm{Pt}(\mathrm{IV}){ }^{59,116}$

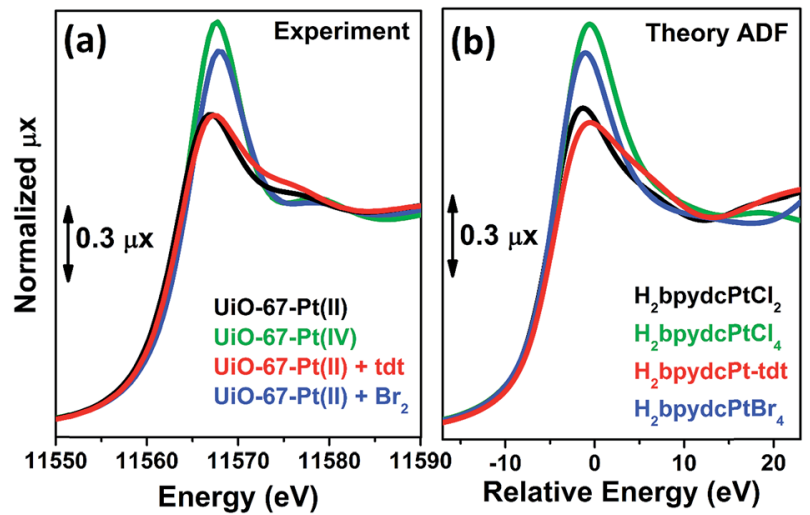

Fig. 4 Part (a): experimental Pt L-3-edge XANES spectra of UiO-67-Pt(vi) (green) and of UiO-67-Pt(II) before (red line) and after interaction with $\mathrm{H}_{2}$ tdt (blue line) and $\mathrm{Br}_{2}$ (green line). Part (b): as for part (a), theoretical spectra computed with ADF code. 
On a more quantitative ground, simulation of the XANES spectra, on the $\mathrm{H}_{2}$ bpydcPtCl ${ }_{4}, \mathrm{H}_{2}$ bpydcPtCl $2, \mathrm{H}_{2}$ bpydcPt-tdt and $\mathrm{H}_{2}$ bpydcPtBr ${ }_{4}$ molecular fragments (Fig. 4b), was able to reproduce correctly the variation of the white line intensity, and post edge features. ${ }^{116}$ The data reported in Fig. 4 testifies the potentialities of the XANES simulations. ${ }^{117}$

\subsection{Tuning the Pt site population inside UiO-67-Pt MOF by controlled $\mathrm{H}_{2}$-TPR}

The interesting results obtained by us in the Pt-functionalisation of UiO-67 (here summarized in Section 3.1), together with the relevance of hosting reactive metal NPs inside the MOF cavities, ${ }^{51-58}$ encouraged us to investigate different activation conditions in order to be able to tune the population of Pt phases inside functionalised UiO-67, from isolated Pt sites anchored to the MOF framework with Pt exhibiting two coordination vacancies (potentially interesting for $\mathrm{C}-\mathrm{H}$ bond activation) to small Pt NPs (potentially interesting for hydrogenation reactions).

In the following two subsections, we report the XANES and EXAFS results, and the corresponding data analysis, obtained by thermal activation of the functionalised UiO-67-Pt MOF under an inert flow (He, 3.2.1) and under a concentrated $\mathrm{H}_{2}$ flow $\left(10 \% \mathrm{H}_{2}\right.$ in $\left.\mathrm{He}, 3.2 .2\right)$. In both cases the EXAFS data have been analysed using a parametric refinement allowing us to obtain, along the activation procedure, the first shell Pt coordination numbers $\left(N_{\mathrm{Pt}-\mathrm{N}}, N_{\mathrm{Pt}-\mathrm{Cl}}\right.$ and, when present, $\left.N_{\mathrm{Pt}-\mathrm{Pt}}\right)$ with the minimal correlation possible with the corresponding Debye-Waller parameters. From such data, the fractions of the different platinum phases present in the sample have been obtained, as outlined hereafter. The following nomenclature has been adopted for the different relative fractions of $\mathrm{Pt}$ species formed in the experiments: $f_{\mathrm{bpyCl}_{2}}$ corresponds to Pt atoms coordinated to the bpydc linker in the MOF framework, still containing the $\mathrm{Cl}$ ligands; $f_{\mathrm{bpy}}$ stands for Pt atoms coordinated to the bpydc linker in the MOF framework after the loss of two Cl ligands; $f_{\text {extra }}$ represents non-aggregated extra-framework Pt atoms; and $f_{\mathrm{NPs}}$ stands for extra-framework Pt atoms aggregated in NPs. While the $f_{\mathrm{bpyCl}_{2}}, f_{\mathrm{bpy}}$ and $f_{\mathrm{NPs}}$ fractions correspond to well defined Pt species, $f_{\text {extra }}$ does not. Although it is fully reasonable to infer that, once the Pt-N bonds within the framework are broken, Pt atoms will behave as isolated species for a while before being incorporated into a pre-existing NP (or before interacting with other isolated Pt atoms to produce a new NP), the local environment of such Pt species is very difficult to predict. Most probably such Pt atoms will experience a large variety of different local environments resulting in an average contribution to the measured EXAFS spectrum that is very low because of heterogeneity. This fact has been very well documented by EXAFS studies on Fe-substituted zeolites showing that the amplitude of the experimental EXAFS signal is strongly dimmed once Fe atoms migrate from the framework into extra-framework sites, ${ }^{118-120}$ contributing only in the very short $k$-range (typically up to $6 \AA^{-1}$ ).

3.2.1. Thermal activation of UiO-67-Pt under inert atmosphere. Fig. 5a and b report the evolution of the Pt $\mathrm{L}_{3}$-edge XANES and EXAFS spectra during in situ thermal activation of the functionalized UiO-67-Pt MOF under an inert He flow in the 300-750 K range. The evolution of both XANES and EXAFS spectra observed under an inert flow is very similar to what is observed working under a diluted $\mathrm{H}_{2}$ flow, ${ }^{59}$ see Fig. 2a for the EXAFS part. Also, in this case we did not observe any evidence of Pt-Pt bonds in the FT of the EXAFS data (Fig. 5b), evidencing the 

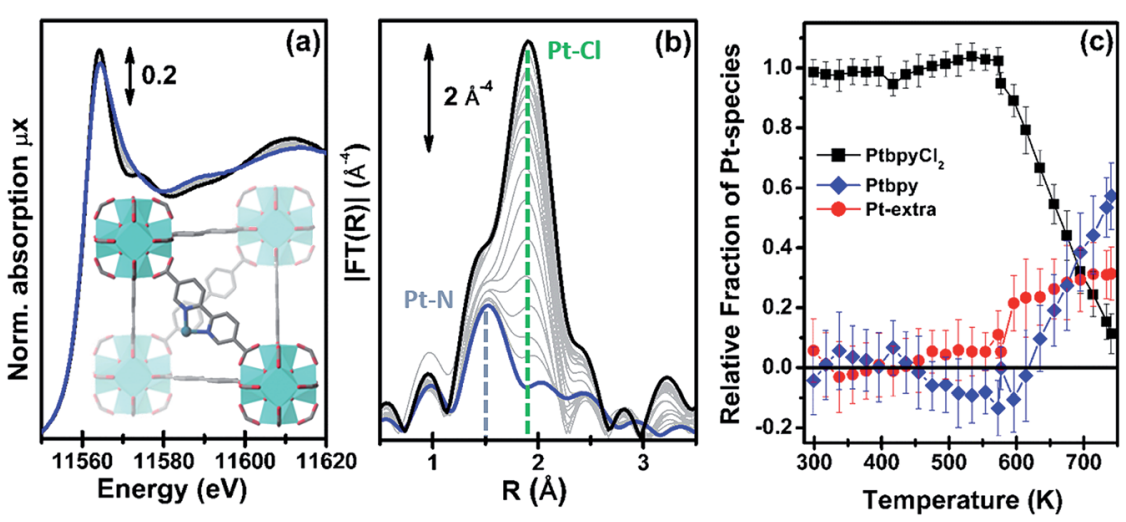

Fig. 5 Part (a): evolution of the $\mathrm{Pt}_{3}$-edge XANES spectra during in situ thermal activation of the functionalized UiO-67-Pt MOF under an inert He flow in the 300-750 K range. The inset shows a cartoon description of the dominant final phase (framework-coordinated Pt atom that has lost the two $\mathrm{Cl}$ ligands). Part (b): as part (a) for the $k^{3}$-weighted, phase uncorrected FT of the corresponding EXAFS data. Also highlighted with blue and green dashed lines are the typical positions of the $\mathrm{Pt}-\mathrm{N}$ and $\mathrm{Pt}-\mathrm{Cl}$ contributions, respectively. Part (c): fraction of the different Pt phases present in the sample, estimated from the $N_{\mathrm{Pt}-\mathrm{N}}$ and $N_{\mathrm{Pt}-\mathrm{Cl}}$ coordination numbers obtained from the parametric refinement of the whole set of EXAFS data, according to the assumptions reported in eqn (2).

absence of formation of Pt metal NPs. According to this evidence, the fractions of the remaining three Pt phases are obtained as follows:

$$
f_{\mathrm{NPs}}=0 ; f_{\mathrm{bpyCl}_{2}}=N_{\mathrm{Cl}} / 2 ; f_{\text {extra }}=\left(2-N_{\mathrm{N}}\right) / 2 ; f_{\mathrm{bpy}}=1-f_{\mathrm{bpyCl}_{2}}-f_{\text {extra }}
$$

The analysis of the evolution during the activation experiment of the relative fractions of the different Pt phases performed according to eqn (2) is reported in Fig. $5 \mathrm{c}$. Up to $550 \mathrm{~K}$, within the experimental errors, $f_{\mathrm{bpyCl}_{2}}=1$ and $f_{\text {extra }}=f_{\text {bpy }}=0$. Then, $f_{\mathrm{bpyCl}_{2}}$ starts to rapidly decrease down to 0.1 in an almost linear fashion with the increasing temperature; an opposite trend is observed for $f_{\mathrm{bpy}}$, reaching 0.6 at $750 \mathrm{~K}$, while $f_{\text {extra }}$ exhibits an abrupt increase at $c a .570 \mathrm{~K}$, and subsequently stabilizes at around 0.3 .

3.2.2. Thermal activation of UiO-67-Pt under concentrated $\mathbf{H}_{2}$ flow. Evolution of the $\mathrm{Pt}_{\mathrm{L}_{3}}$-edge XANES and EXAFS spectra during the in situ $\mathrm{H}_{2}$-TPR experiment of the $\mathrm{PtCl}_{2}\left(\mathrm{H}_{2}\right.$ bpydc) functionalized UiO-67-Pt(II) MOF performed in a concentrated $\mathrm{H}_{2}$ flow $\left(10 \% \mathrm{H}_{2}\right.$ in $\left.\mathrm{He}\right)$ is reported in parts (a) and (b) of Fig. 6, respectively. In this case, the experiment consists of a linear temperature increase up to $625 \mathrm{~K}$ with a heating ramp of $5 \mathrm{~K} \mathrm{~min}^{-1}$, followed by almost $3 \mathrm{~h}$ in isotherm (see the open grey triangles in Fig. 6c).

Different to what was observed in the previous cases, where $N_{\mathrm{Pt}-\mathrm{Cl}}$ started to decrease significantly before $N_{\mathrm{Pt}-\mathrm{N}}$, in the present case both $N_{\mathrm{Pt}-\mathrm{N}}$ and $N_{\mathrm{Pt}-\mathrm{Cl}}$ remain, within the associated error bars, equal to 2 during the whole heating ramp up to $625 \mathrm{~K}$ (indicating $f_{\mathrm{bpyCl}_{2}}=1$ ) and start to decrease in the same way during the isotherm (data not reported for brevity). This indicates that, under a concentrated $\mathrm{H}_{2}$ flow, when framework Pt(II) species lose the Pt-Cl bond they 

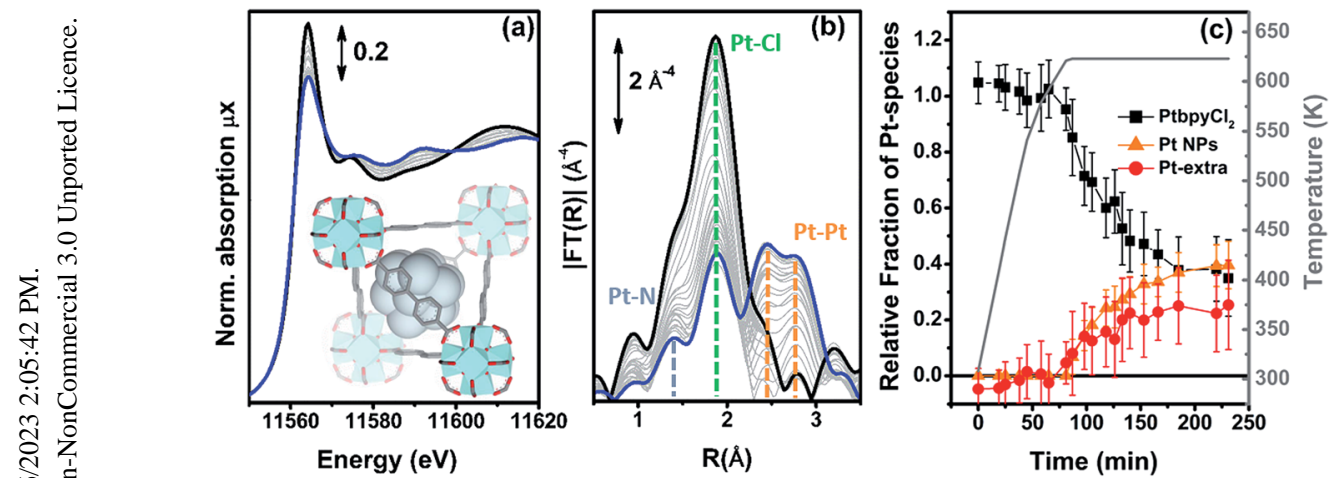

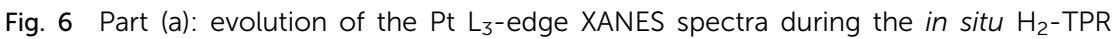
experiment of the $\mathrm{PtCl}_{2}\left(\mathrm{H}_{2}\right.$ bpydc) functionalized UiO-67-Pt(I) MOF performed in a concentrated $\mathrm{H}_{2}$ flow $\left(10 \% \mathrm{H}_{2}\right.$ in $\left.\mathrm{He}\right)$. The inset shows a cartoon description of the dominant final phase (metal NPs). Part (b): as part (a) for the $k^{3}$-weighted, phase uncorrected FT of the corresponding EXAFS data. Also highlighted with blue, green and orange dashed lines are the typical positions of the $\mathrm{Pt}-\mathrm{N}, \mathrm{Pt}-\mathrm{Cl}$ and $\mathrm{Pt}-\mathrm{Pt}$ contributions, respectively. Part (c), full black, red and orange symbols, left ordinate axis: fraction of the different Pt phases present in the sample, estimated from the $N_{\mathrm{Pt}-\mathrm{N}}, N_{\mathrm{Pt}-\mathrm{Cl}}$ and $N_{\mathrm{Pt}-\mathrm{Pt}}$ coordination numbers obtained from the parametric refinement in the whole set of EXAFS data, according to the assumptions reported in eqn (5). Part (c), open grey triangles, right ordinate axis: evolution of the sample temperature with time, highlighting the linear increase up to $625 \mathrm{~K}$ in $65 \mathrm{~min}$ followed by $2 \mathrm{~h} 55 \mathrm{~min}$ in isotherm.

almost simultaneously also lose the Pt-N bond and thus the connectivity with the MOF framework, thus becoming extra-framework species. Based on this evidence, we can assume $f_{\mathrm{bpy}}=0$, while $f_{\mathrm{bpyCl}_{2}}$ can be determined by averaging the contribution of both Pt-Cl and Pt-N bonds: $f_{\mathrm{bpyCl}_{2}}=\left(N_{\mathrm{Cl}} / 2+N_{\mathrm{N}} / 2\right) / 2$.

A second important difference, very evident in Fig. $6 \mathrm{~b}$, is the structured signal in the 2.5-3.5 $\AA$ range, typical of the single and multiple scattering Pt-Pt contributions of the fcc metal phase, testifying the formation of Pt NPs. Hence, the EXAFS data analysis also provides a first shell $N_{\mathrm{Pt}-\mathrm{Pt}}$ coordination number. Unfortunately the fraction of Pt atoms in the NPs phase cannot be straightforwardly deduced from the $N_{\mathrm{Pt}-\mathrm{Pt}}$ number obtained from the EXAFS data analysis, because the average coordination number of a fcc NP increases with the particle size, asymptotically reaching the value of 12 of the bulk in the first shell. ${ }^{121-125}$ Consequently, the $N_{\mathrm{Pt}-\mathrm{Pt}} \leftrightarrow f_{\mathrm{NPs}}$ relationship can be established only if the particle size distribution has been determined by an independent SAXS $^{126-133}$ or $\mathrm{TEM}^{74,124,133-135}$ study.

Indeed, at the end of the $\mathrm{H}_{2}$-TPR experiment reported in Fig. 6, the sample was cooled down to $300 \mathrm{~K}$ under He flow, recovered and subjected to a TEM study (see Fig. $7 \mathrm{~b}$ and $\mathrm{c}$ for two selected micrographs taken at different magnifications), giving the particle size distribution $w_{\mathrm{P}}\left(d_{\mathrm{i}}\right)$ reported in Fig. 7a (orange bars) and obtained by selecting the NPs in 12 classes of amplitude $1 \mathrm{~nm} . w_{\mathrm{P}}\left(d_{\mathrm{i}}\right)$ reports the fraction of NPs that have a diameter $d$ falling in the class centred in $d_{\mathrm{i}}$ and results in an average NP diameter of $\langle d\rangle_{\mathrm{P}}=3.5 \mathrm{~nm}$ with a standard deviation of $1.2 \mathrm{~nm}$. The orange NP distribution $w_{\mathrm{P}}\left(d_{\mathrm{i}}\right)$ is the standard output from a TEM analysis, but is however not the correct one to be used to extrapolate the average coordination number measured in the EXAFS study. Indeed, the measured EXAFS signal is the 


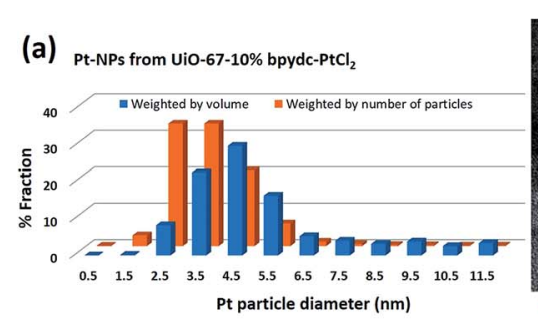

Fig. 7 Part (a): Pt NP distributions (weighted by number of particles (orange) or by volume (blue): $w_{\mathrm{P}}\left(d_{\mathrm{i}}\right)$ and $w_{\mathrm{V}}\left(d_{\mathrm{i}}\right)$, respectively, see eqn (3)) obtained from the TEM analysis of the $\mathrm{PtCl}_{2}\left(\mathrm{H}_{2}\right.$ bpydc) functionalized UiO-67-Pt(॥) MOF measured after the $\mathrm{H}_{2}$-TPR XAS experiment reported in Fig. 6. Parts (b) and (c) report two micrographs at different magnifications.

average signal coming from all the Pt atoms in the sample. This means that a large particle contributes more to the EXAFS signal than a small one, because it contains more atoms. The orange $w_{\mathrm{P}}\left(d_{\mathrm{i}}\right)$ distribution, weighted by particles, has to be corrected by weighting for the corresponding volume fraction into $w_{\mathrm{v}}\left(d_{\mathrm{i}}\right)$, defined as follows:

$$
w_{\mathrm{V}}\left(d_{\mathrm{i}}\right)=\frac{4 \pi}{3 V}\left(\frac{1}{2} d_{\mathrm{i}}\right)^{3} w_{\mathrm{P}}\left(d_{\mathrm{i}}\right), \text { where : } V=\sum_{i=1}^{n} \frac{4 \pi}{3}\left(\frac{1}{2} d_{\mathrm{i}}\right)^{3} w_{\mathrm{P}}\left(d_{\mathrm{i}}\right) .
$$

The volume-weighted NP distribution, obtained from $w_{\mathrm{P}}\left(d_{\mathrm{i}}\right)$ via eqn (3), is reported in Fig. 7a (orange bars) and results in a (volume-weighted) average NP diameter of $\langle d\rangle_{\mathrm{V}}=5.5 \mathrm{~nm}$ with a standard deviation of $1.5 \mathrm{~nm}$. Comparing $w_{\mathrm{P}}\left(d_{\mathrm{i}}\right)$ and $w_{\mathrm{V}}\left(d_{\mathrm{i}}\right)$, the more important role played by the high- $d$ region is evident. Knowing the average coordination number of an fcc NP with a given diameter, $N\left(d_{\mathrm{i}}\right)$, the volume-weighted NP distribution allows us to obtain the average coordination number of the whole particle distribution estimated from the TEM analysis $\left(N_{\text {TEM }}\right)$ as:

$$
N_{\mathrm{TEM}}=\sum_{i=1}^{n} N\left(d_{\mathrm{i}}\right) w_{\mathrm{V}}\left(d_{\mathrm{i}}\right)=10.9
$$

Once $N_{\text {TEM }}$ has been determined, the fraction of Pt atoms occurring as NPs is obtained as $f_{\mathrm{NPs}}=N_{\mathrm{Pt}} / N_{\mathrm{TEM}}$, while the fraction of Pt atoms in non-aggregated extra-framework positions is obtained by the difference between the unit and the sum of the other two fractions. Summarizing:

$$
f_{\mathrm{bpy}}=0 ; f_{\mathrm{bpyCl}_{2}}=\left(N_{\mathrm{Cl}} / 2+N_{\mathrm{N}} / 2\right) / 2 ; f_{\mathrm{NPs}}=N_{\mathrm{Pt}} / N_{\mathrm{TEM}} ; f_{\mathrm{extra}}=1-f_{\mathrm{bpyCl}_{2}}-f_{\mathrm{NPs}}
$$

The evolution of the relative fractions of the different Pt phases during the in situ $\mathrm{H}_{2}$-TPR experiment in a concentrated $\mathrm{H}_{2}$ flow is summarized in Fig. $6 \mathrm{c}$. The weakness of this approach is the fact that we assume the same NP size distribution along the whole $\mathrm{H}_{2}$-TPR experiment. Nonetheless, this approach provides a correct evaluation of $f_{\mathrm{NPs}}$ for the last points of the treatment, which is the required information in the view of potential application in catalysis. 
Within the experimental error, along the whole heating ramp up to $625 \mathrm{~K}$, Pt atoms maintain the same square planar coordination with two nitrogen and two chlorine ligands in their first coordination shell. During the isotherm, they break simultaneously the bonds with both the Cl ligands and the MOF framework, becoming extra-framework species, that progressively aggregate into NPs. After $3 \mathrm{~h}$ of isotherm at $625 \mathrm{~K}$ the distribution among the different Pt phases reaches an asymptotic equilibrium.

\subsection{Structure and redox properties of isolated $\mathrm{Cu}$ sites in UiO-67-Cu MOF}

The interesting results obtained on the Pt-functionalised UiO-67 MOF encouraged us to extend the study using other metals. Because of its interesting redox chemistry, our first choice was on copper. We consequently prepared a $\mathrm{Cu}-$ functionalized UiO-67 MOF by contacting the bpydc-containing UiO-67-bpy MOF with a $\mathrm{CuCl}_{2}$ dihydrate precursor. ${ }^{60}$ The synthesis method succeeded in grafting isolated $\mathrm{Cu}$ (II) ions on the functionalised bpydc linkers of the UiO-67 framework but, contrary to what was expected, the local environment of copper was not composed of two nitrogen and two chlorine atoms as it was the case for the Pt-functionalised MOF (see Fig. 1b and c).

Indeed, just from a first simple comparison of the XANES (Fig. 8a) and EXAFS (Fig. 8b) data collected on as-prepared UiO-67-Cu (black) and on the tBbpyCuCl model compound (green, where $\mathrm{Cu}$ (II) is in a square planar geometry coordinating $2 \mathrm{~N}$ and $2 \mathrm{Cl}$ atoms, see Fig. 8c) clearly testifies that the local environment of $\mathrm{Cu}$ atoms in the two materials is significantly different. The EXAFS data clearly shows a lack of an EXAFS signal in the (1.5-2.1) A region in the MOF, suggesting the presence of only one $\mathrm{Cl}$ atom in the first coordination shell of the $\mathrm{Cu}(\mathrm{II})$.
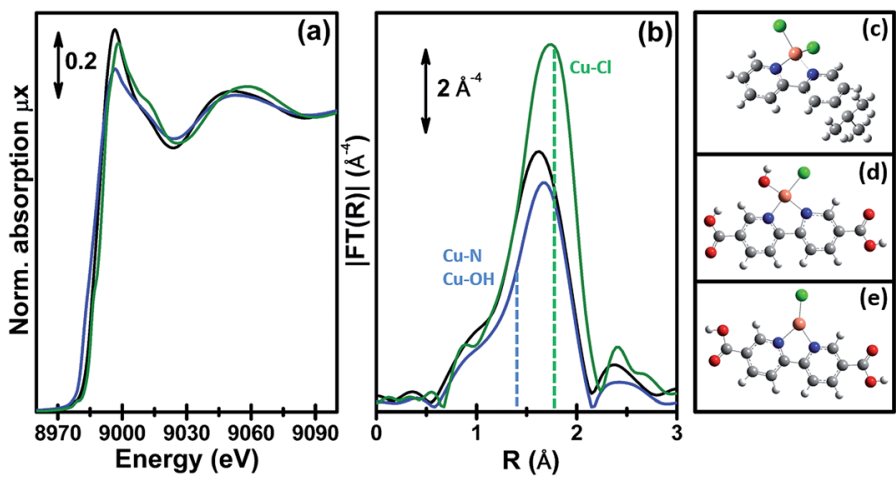

Fig. 8 Part (a): Cu K-edge XANES spectra of the tBbpyCuCl${ }_{2}$ model compound (green) and of the UiO-67-Cu MOF before and after the in situ thermal activation in an $\mathrm{N}_{2}$ flow (black and blue spectra, respectively). Part (b): as part (a) for the $k^{3}$-weighted, phase uncorrected FT of the corresponding EXAFS data. Also highlighted with blue and green dashed lines are the typical positions of the $(\mathrm{Cu}-\mathrm{N}$ or $\mathrm{Cu}-\mathrm{OH})$ and $\mathrm{Cu}-\mathrm{Cl}$ contributions, respectively. Part (c): structure of the $\mathrm{tBbpyCuCl}$ model compound as obtained from the single-crystal XRD refinement (data collected at $100 \mathrm{~K}$ ). Parts (d) and (e): DFT-optimized structures of the $\mathrm{Cu}(\|) \mathrm{ClOH}\left(\mathrm{H}_{2}\right.$ bpydc) and $\mathrm{Cu}(\mathrm{l}) \mathrm{Cl}\left(\mathrm{H}_{2}\right.$ bpydc) complexes used as a starting point for the EXAFS fits of the UiO-67-Cu MOF before and after the in situ thermal activation. Atom colour code: $\mathrm{Cu}$ : orange; $\mathrm{O}$ : red; $\mathrm{N}$ : blue; $\mathrm{Cl}$ : green, $\mathrm{C}$ : gray; $\mathrm{H}$ : white. Previously unpublished figure reporting spectra and structures from ref. 60 . 
Fig. 9 reports the XANES spectra (part a) and the $k^{3}$-weighted, phase uncorrected (part b) FT EXAFS spectra for the exemplificative case of UiO-67-Cu during the thermal treatment in an inert gas flow, from RT (as-prepared state, black) to $523 \mathrm{~K}$ (blue). Spectra collected at intermediate temperatures are also reported, as thin gray lines.

The XANES spectrum for the as-prepared material is characterized by the absence of any defined pre-edge/edge peaks, and by a rather intense white line feature at $\sim 8996.6 \mathrm{eV}$, typical of $\mathrm{Cu}$ (II) centres coordinated to water molecules and, eventually, $\mathrm{OH}$ groups. ${ }^{136-141}$ As also supported by the comparison with the tBbpyCuCl${ }_{2}$ model compound, the overall shape and the edge energy position in the XANES spectrum of the as-prepared material are consistent with a $2+$ oxidation state of copper. The spectral changes observed during thermal activation involve a clear decrease of the white line feature, accompanied by a significant shift of the absorption edge towards lower energies ( $c a .3 .6 \mathrm{eV}$ ), as evaluated by monitoring the energy position of the first main maximum of the first derivative spectra. ${ }^{142,143}$ At the end of the heating ramp, a shoulder starts to be distinguishable in the XANES edgerising region at $c a .8983 \mathrm{eV}$, falling in an energy range typical of two- or threecoordinated $\mathrm{Cu}(\mathrm{I})$ sites. ${ }^{\mathbf{1 4 4 , 1 4 5}}$ These evidences suggest a ligand loss process associated with the reduction of the starting $\mathrm{Cu}$ (II) sites into $\mathrm{Cu}(\mathrm{I})$, as thermal treatment proceeds. Such spectral modifications are also accompanied by the sample color change from green to light-green/white as the temperature increases, supporting the formation of coordinatively unsaturated $\mathrm{Cu}(\mathrm{I})$ sites after mild thermal treatment in an inert atmosphere.

We succeeded in reproducing the EXAFS and XANES spectra of the as prepared UiO-67-Cu MOF using as a starting model that obtained from the optimization of
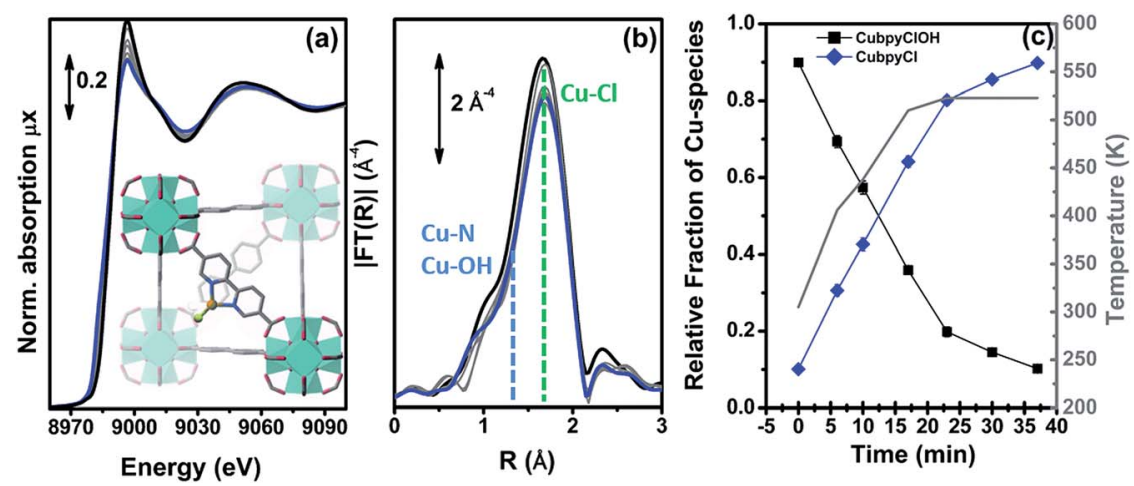

Fig. 9 Part (a): evolution of the $\mathrm{Cu}$ K-edge XANES spectra during the in situ thermal activation in an $\mathrm{N}_{2}$ flow of the $\mathrm{CuClOH}\left(\mathrm{H}_{2}\right.$ bpydc) functionalized UiO-67-Cu(I) MOF in the 300-523 $\mathrm{K}$ range. The inset shows a cartoon description of the dominant final phase (framework-coordinated $\mathrm{Cu}(\mathrm{I})$ species with a $\mathrm{Cl}$ ligand). Part (b): as part (a) for the $k^{3}$-weighted, phase uncorrected FT of the corresponding EXAFS data. Also highlighted with blue and green dashed lines are the typical positions of the $(\mathrm{Cu}-\mathrm{N}$ or $\mathrm{Cu}-\mathrm{OH})$ and $\mathrm{Cu}-\mathrm{Cl}$ contributions, respectively. Part (c), full black and blue symbols, left ordinate axis: fraction of the different Cu phases present in the sample estimated according to a linear combination of the XANES spectra of the starting and final phases. Part (c), open grey triangles, right ordinate axis: evolution of the sample temperature with time, highlighting the linear increase up to $523 \mathrm{~K}$ in $23 \mathrm{~min}$ followed by $13 \mathrm{~min}$ in isotherm. Previously unpublished figure reporting spectra from ref. 60. 
the $[\mathrm{Cu}(\mathrm{II})($ bpydc) $(\mathrm{OH}) \mathrm{Cl}]$ complex (see Fig. 8d) at the DFT level of theory with VASP 5.3 code, ${ }^{146,147}$ using a kinetic energy cut-off for the plane-wave basis set of $400 \mathrm{eV}$. The EXAFS-optimized distances were: $R_{\mathrm{Cu}-\mathrm{OH}}=1.91 \pm 0.01 \AA, R_{\mathrm{Cu}-\mathrm{N}}=$ $2.026 \pm 0.006 \AA$ and $R_{\mathrm{Cu}-\mathrm{Cl}}=2.265 \pm 0.006 \AA$, in reasonable agreement with the DFT-optimized distances. ${ }^{60}$ The same holds for the DFT-optimized $[\mathrm{Cu}(\mathrm{I})($ bpydc)Cl] complex (see Fig. 8e), that was able to correctly reproduce the EXAFS spectrum of the $\mathrm{N}_{2}$-activated UiO-67-Cu MOF, resulting in $R_{\mathrm{Cu}-\mathrm{N}}=1.989 \pm$ $0.008 \AA$ and $R_{\mathrm{Cu}-\mathrm{Cl}}=2.249 \pm 0.007 \AA$. The progressive evolution from the $[\mathrm{Cu}(\mathrm{II})($ bpydc) $(\mathrm{OH}) \mathrm{Cl}]$ complex into the $[\mathrm{Cu}(\mathrm{I})(\mathrm{bpydc}) \mathrm{Cl}]$ complex upon thermal activation in an inert atmosphere has been quantified by linear combination of the XANES spectra and is reported in Fig. 9c.

Further insights into the nature and reactivity of these $[\mathrm{Cu}(\mathrm{I})(\mathrm{bpydc}) \mathrm{Cl}]$ complexes, representing an interesting platform for future experiments on $\mathrm{Cu}(\mathrm{I})$-catalyzed reactions, were achieved by monitoring with XAS and FTIR the interaction of the thermally-treated material with the CO probe molecule. Both techniques pointed out the efficient and reversible formation of $\mathrm{Cu}(\mathrm{I})$-monocarbonyl adducts with $\mathrm{CO}$, compatible with $[\mathrm{Cu}(\mathrm{I})(\mathrm{bpydc})(\mathrm{CO}) \mathrm{Cl}]$ species as highlighted by EXAFS fitting.

The overall picture is confirmed by XANES simulations performed with the FDMNES $\operatorname{code}^{117}$ for the key experimental conditions investigated, including asprepared MOFs in air, after thermal treatment in $\mathrm{N}_{2}$-flux and upon interaction with $\mathrm{CO}^{60}$

\section{Conclusions}

A post-synthesis functionalisation approach has been successfully employed to graft $\mathrm{Pt}(\mathrm{II})$ and $\mathrm{Cu}(\mathrm{II})$ atoms on the UiO-67 MOF functionalized with $10 \%$ of bpydc ligands. The in situ EXAFS analysis, for all the series of samples at RT, demonstrates that the Pt atoms are grafted to the bpydc-linkers in a square planar coordination with two $\mathrm{Cl}$ and two $\mathrm{N}$ atomic neighbors. XAS spectroscopy was used in operando conditions to study the activation of UiO-67-Pt functionalized MOFs, demonstrating that, by tuning the activation conditions, two types of catalytically active sites can be formed in the cavities of the MOF: (i) isolated, highly uncoordinated framework $>\mathrm{Pt}$ species bound to the two $\mathrm{N}$ atoms of the functionalising bpydc linkers of the MOF and (ii) Pt NPs. XAS was used for monitoring the temperature-dependent behavior of UiO-67-Pt during the thermal activation process, in different gas feeds (pure $\mathrm{He}, 3 \% \mathrm{H}_{2} / \mathrm{He}$ and $10 \% \mathrm{H}_{2} / \mathrm{He}$ ). EXAFS analysis of the data collected during operando $\mathrm{H}_{2}$-TPR was performed using the Einstein model to predict the temperature dependence of the Debye-Waller factors and to reduce the correlation among the optimized parameters. In a $10 \%$ $\mathrm{H}_{2} / \mathrm{He}$ flow, EXAFS clearly shows the loss of both $\mathrm{Cl}$ and $\mathrm{N}$ scattering contributions, while the rising of an intense signal at around $2.7 \AA$, associated with the PtPt contributions, unambiguously indicates Pt NPs formation. Conversely, in a pure He flow, the only significant change observed during TPR is the progressive decrease of the $\mathrm{Pt}-\mathrm{Cl}$ single scattering contribution, leading to the conclusion that the Pt grafted to the bpydc-linkers remains naked. In general, Pt sites in UiO67-Pt MOFs tend to form Pt NPs in the presence of $\mathrm{H}_{2}$ and remain naked, but still grafted to the bpydc-linkers, in an inert gas flow. This study demonstrates that two families of different catalytically active Pt sites can be generated in UiO-67-Pt 
MOFs by properly tuning the activation conditions. In situ IR, ex situ TEM and catalytic tests support the operando XAS study.

By combining in situ and operando XAS and FTIR spectroscopy, we also assessed the successful incorporation of well-defined $\mathrm{Cu}$ complexes in the UiO-67 framework in the form of the $\left[\mathrm{Cu}(\mathrm{II}) \mathrm{ClOH}\left(\mathrm{H}_{2}\right.\right.$ bpydc $\left.)\right]$ complex, that evolves into $\left[\mathrm{Cu}(\mathrm{I}) \mathrm{Cl}\left(\mathrm{H}_{2}\right.\right.$ bpydc $\left.)\right]$ upon thermal activation in an inert atmosphere. We explored the local coordination geometry, redox properties and reactivity of the dominant $\mathrm{Cu}$ species formed in different conditions relevant to potential future applications in catalysis. EXAFS fits and XANES simulations, based on DFT-optimized geometries, yielded detailed structural and electronic information on the major Cu-species formed.

The methodology of the post-synthesis functionalisation of the UiO-67 MOF, here described for $\mathrm{PtCl}_{2}$ and $\mathrm{CuCl}_{2}$, has been recently successfully extended using $\mathrm{RhCl}_{3}$ and $\mathrm{IrCl}_{3}$ precursors, while a first attempt to insert gold via $\mathrm{HAuCl}_{4}$ as the precursor failed. ${ }^{148}$ The same strategy has been followed by the group of Long, who succeeded in preparing UiO-67-M grafting $\mathrm{NiBr}_{2},{ }^{149} \mathrm{CuCl}_{2},{ }^{150} \mathrm{CoCl}_{2},{ }^{150}$ $\mathrm{FeBr}_{2},{ }^{150}$ and $\mathrm{Cr}(\mathrm{CO})_{4}{ }^{150}$ on functionalized $\mathrm{H}_{2}$ bpydc linkers in UiO-67. In this regard, very interesting are also the works of the Lin group who synthesized UiO66-like class of MOFs using long $\left[\operatorname{Ir}(\mathrm{ppy})_{2}(\mathrm{bpy})\right]^{+}$-derived dicarboxylate ligands; successive photoreduction of $\mathrm{K}_{2} \mathrm{PtCl}_{4}$ resulted in Pt nanoparticles hosted inside the large MOFs cavities. ${ }^{51}$ Successively, the same group used $\mathrm{Re}(\mathrm{CO})_{3} \mathrm{Cl}$ grafted to $4,4^{\prime}$-(2,2'-bipyridine-5,5'-diyl)dibenzoate ${ }^{151}$ and $\mathrm{FeBr}_{2}$ grafted to $4,4^{\prime}$-(1,10-phenanthroline-3,8-diyl)dibenzoic acid $^{152}$ linkers to obtain metal functionalized MOFs with UiO-66-like structure with interesting catalytic activities. Of interest is also the post-synthesis functionalization strategy used to insert the $\beta$-diketiminate functionality in a MOF of UiO-topology. Metalation of the $\beta$-diketiminateMOF with iron, copper, and cobalt metal salts afforded the desired MOF-supported $\beta$-diketiminate- $\mathrm{M}$ complexes $(\mathrm{M}=\mathrm{Fe}, \mathrm{Cu}$, and $\mathrm{Co}) .{ }^{88}$

\section{Acknowledgements}

LB, ALB, AAG, AVS and CL acknowledge the Megagrant of the Russian Federation Government to support scientific research at the Southern Federal University, no. 14.Y26.31.0001. KAL acknowledges the support from the Russian Foundation for Basic Research, Project no. 16-32-00572 mol_a. The authors are grateful to MAXlab for the allocation of the beam time (proposal 20140449) and to Dr Stefan Carlson for the technical support during the experiments at the I811 beamline.

\section{Notes and references}

1 S. L. James, Chem. Soc. Rev., 2003, 32, 276-288.

2 J. L. C. Rowsell and O. M. Yaghi, Microporous Mesoporous Mater., 2004, 73, 3-14.

3 G. Ferey, Chem. Soc. Rev., 2008, 37, 191-214.

4 N. Stock and S. Biswas, Chem. Rev., 2012, 112, 933-969.

5 T. R. Cook, Y. R. Zheng and P. J. Stang, Chem. Rev., 2013, 113, 734-777.

6 H. Furukawa, K. E. Cordova, M. O'Keeffe and O. M. Yaghi, Science, 2013, 341, 974-987. 
7 V. V. Butova, M. A. Soldatov, A. A. Guda, K. A. Lomachenko and C. Lamberti, Russ. Chem. Rev., 2016, 85, 280-307.

8 Z. Q. Wang and S. M. Cohen, Chem. Soc. Rev., 2009, 38, 1315-1329.

9 K. K. Tanabe and S. M. Cohen, Chem. Soc. Rev., 2011, 40, 498-519.

10 D. Zhao, D. J. Timmons, D. Q. Yuan and H. C. Zhou, Acc. Chem. Res., 2011, 44, 123-133.

11 S. M. Cohen, Chem. Rev., 2012, 112, 970-1000.

12 F. A. A. Paz, J. Klinowski, S. M. F. Vilela, J. P. C. Tome, J. A. S. Cavaleiro and J. Rocha, Chem. Soc. Rev., 2012, 41, 1088-1110.

13 W. G. Lu, Z. W. Wei, Z. Y. Gu, T. F. Liu, J. Park, J. Park, J. Tian, M. W. Zhang, Q. Zhang, T. Gentle, M. Bosch and H. C. Zhou, Chem. Soc. Rev., 2014, 43, 5561-5593.

14 J. D. Evans, C. J. Sumby and C. J. Doonan, Chem. Soc. Rev., 2014, 43, 59335951.

15 D. Farrusseng, S. Aguado and C. Pinel, Angew. Chem., Int. Ed., 2009, 48, 75027513.

16 J. Lee, O. K. Farha, J. Roberts, K. A. Scheidt, S. T. Nguyen and J. T. Hupp, Chem. Soc. Rev., 2009, 38, 1450-1459.

17 L. Q. Ma, C. Abney and W. B. Lin, Chem. Soc. Rev., 2009, 38, 1248-1256.

18 A. Corma, H. Garcia and F. Xamena, Chem. Rev., 2010, 110, 4606-4655.

19 M. Ranocchiari and J. A. van Bokhoven, Phys. Chem. Chem. Phys., 2011, 13, 6388-6396.

20 A. Dhakshinamoorthy and H. Garcia, Chem. Soc. Rev., 2012, 41, 5262-5284.

21 M. Yoon, R. Srirambalaji and K. Kim, Chem. Rev., 2012, 112, 1196-1231.

22 Metal Organic Frameworks as Heterogeneous Catalysts, ed. F. Xamena and J. Gascon, Royal Society of Chemistry, Cambridge, 2013.

23 J. W. Liu, L. F. Chen, H. Cui, J. Y. Zhang, L. Zhang and C. Y. Su, Chem. Soc. Rev., 2014, 43, 6011-6061.

24 A. H. Chughtai, N. Ahmad, H. A. Younus, A. Laypkov and F. Verpoort, Chem. Soc. Rev., 2015, 44, 6804-6849.

25 S. S. Y. Chui, S. M. F. Lo, J. P. H. Charmant, A. G. Orpen and I. D. Williams, Science, 1999, 283, 1148-1150.

26 C. Prestipino, L. Regli, J. G. Vitillo, F. Bonino, A. Damin, C. Lamberti, A. Zecchina, P. L. Solari, K. O. Kongshaug and S. Bordiga, Chem. Mater., 2006, 18, 1337-1346.

27 S. Bordiga, L. Regli, F. Bonino, E. Groppo, C. Lamberti, B. Xiao, P. S. Wheatley, R. E. Morris and A. Zecchina, Phys. Chem. Chem. Phys., 2007, 9, 2676-2685.

28 F. Bonino, S. Chavan, J. G. Vitillo, E. Groppo, G. Agostini, C. Lamberti, P. D. C. Dietzel, C. Prestipino and S. Bordiga, Chem. Mater., 2008, 20, 49574968.

29 S. Chavan, J. G. Vitillo, E. Groppo, F. Bonino, C. Lamberti, P. D. C. Dietzel and S. Bordiga, J. Phys. Chem. C, 2009, 113, 3292-3299.

30 P. D. C. Dietzel, P. A. Georgiev, J. Eckert, R. Blom, T. Strassle and T. Unruh, Chem. Commun., 2010, 46, 4962-4964.

31 E. D. Bloch, L. J. Murray, W. L. Queen, S. Chavan, S. N. Maximoff, J. P. Bigi, R. Krishna, V. K. Peterson, F. Grandjean, G. J. Long, B. Smit, S. Bordiga, C. M. Brown and J. R. Long, J. Am. Chem. Soc., 2011, 133, 14814-14822.

32 J. H. Cavka, S. Jakobsen, U. Olsbye, N. Guillou, C. Lamberti, S. Bordiga and K. P. Lillerud, J. Am. Chem. Soc., 2008, 130, 13850-13851. 
33 L. Valenzano, B. Civalleri, S. Chavan, S. Bordiga, M. H. Nilsen, S. Jakobsen, K. P. Lillerud and C. Lamberti, Chem. Mater., 2011, 23, 1700-1718.

34 S. Chavan, J. G. Vitillo, D. Gianolio, O. Zavorotynska, B. Civalleri, S. Jakobsen, M. H. Nilsen, L. Valenzano, C. Lamberti, K. P. Lillerud and S. Bordiga, Phys. Chem. Chem. Phys., 2012, 14, 1614-1626.

35 S. Øien, D. Wragg, H. Reinsch, S. Svelle, S. Bordiga, C. Lamberti and K. P. Lillerud, Cryst. Growth Des., 2014, 14, 5370-5372.

36 G. C. Shearer, S. Chavan, J. Ethiraj, J. G. Vitillo, S. Svelle, U. Olsbye, C. Lamberti, S. Bordiga and K. P. Lillerud, Chem. Mater., 2014, 26, 4068-4071.

37 G. C. Shearer, S. Chavan, S. Bordiga, S. Svelle, U. Olsbye and K. P. Lillerud, Chem. Mater., 2016, 28, 3749-3761.

38 G. C. Shearer, J. G. Vitillo, S. Bordiga, S. Svelle, U. Olsbye and K. P. Lillerud, Chem. Mater., 2016, 28, 7190-7193.

39 K. E. deKrafft, W. S. Boyle, L. M. Burk, O. Z. Zhou and W. B. Lin, J. Mater. Chem., 2012, 22, 18139-18144.

40 S. Jakobsen, D. Gianolio, D. S. Wragg, M. H. Nilsen, H. Emerich, S. Bordiga, C. Lamberti, U. Olsbye, M. Tilset and K. P. Lillerud, Phys. Rev. B: Condens. Matter Mater. Phys., 2012, 86, 125429.

41 A. M. Ebrahim and T. J. Bandosz, ACS Appl. Mater. Interfaces, 2013, 5, 1056510573.

42 M. Lammert, M. T. Wharmby, S. Smolders, B. Bueken, A. Lieb, K. A. Lomachenko, D. De Vos and N. Stock, Chem. Commun., 2015, 51, 12578-12581.

43 F. Nouar, M. I. Breeze, B. C. Campo, A. Vimont, G. Clet, M. Daturi, T. Devic, R. I. Walton and C. Serre, Chem. Commun., 2015, 51, 14458-14461.

44 R. Dalapati, B. Sakthivel, A. Dhakshinamoorthy, A. Buragohain, A. Bhunia, C. Janiak and S. Biswas, CrystEngComm, 2016, 18, 7855-7864.

45 S. J. Garibay and S. M. Cohen, Chem. Commun., 2010, 46, 7700-7702.

46 M. Kandiah, S. Usseglio, S. Svelle, U. Olsbye, K. P. Lillerud and M. Tilset, J. Mater. Chem., 2010, 20, 9848-9851.

47 M. Kandiah, M. H. Nilsen, S. Usseglio, S. Jakobsen, U. Olsbye, M. Tilset, C. Larabi, E. A. Quadrelli, F. Bonino and K. P. Lillerud, Chem. Mater., 2010, 22, 6632-6640.

48 S. M. Chavan, G. C. Shearer, S. Svelle, U. Olsbye, F. Bonino, J. Ethiraj, K. P. Lillerud and S. Bordiga, Inorg. Chem., 2014, 53, 9509-9515.

49 J. Ethiraj, E. Albanese, B. Civalleri, J. G. Vitillo, F. Bonino, S. Chavan, G. C. Shearer, K. P. Lillerud and S. Bordiga, ChemSusChem, 2014, 7, 33823388.

50 S. Chavan, J. G. Vitillo, M. J. Uddin, F. Bonino, C. Lamberti, E. Groppo, K. P. Lillerud and S. Bordiga, Chem. Mater., 2010, 22, 4602-4611.

51 C. Wang, K. E. deKrafft and W. B. Lin, J. Am. Chem. Soc., 2012, 134, 7211-7214. 52 P. H. Ling, J. P. Lei, L. Jia and H. X. Ju, Chem. Commun., 2016, 52, 1226-1229.

53 R. Kardanpour, S. Tangestaninejad, V. Mirkhani, M. Moghadam, I. Mohammadpoor-Baltork, A. R. Khosropour and F. Zadehahmadi, J. Organomet. Chem., 2014, 761, 127-133.

54 W. H. Dong, C. Feng, L. Zhang, N. Z. Shang, S. T. Gao, C. Wang and Z. Wang, Catal. Lett., 2016, 146, 117-125.

55 K. Tulig and K. S. Walton, RSC Adv., 2014, 4, 51080-51083. 
56 J. Yang, L. T. Yang, H. L. Ye, F. Q. Zhao and B. Z. Zeng, Electrochim. Acta, 2016, 219, 647-654.

57 Q. Q. Yuan, D. M. Zhang, L. van Haandel, F. Y. Ye, T. Xue, E. J. M. Hensen and Y. J. Guan, J. Mol. Catal. A: Chem., 2015, 406, 58-64.

58 E. Plessers, D. E. De Vos and M. B. J. Roeffaers, J. Catal., 2016, 340, 136-143.

59 S. Øien, G. Agostini, S. Svelle, E. Borfecchia, K. A. Lomachenko, L. Mino, E. Gallo, S. Bordiga, U. Olsbye, K. P. Lillerud and C. Lamberti, Chem. Mater., 2015, 27, 1042-1056.

60 L. Braglia, E. Borfecchia, L. Maddalena, S. Øien, K. A. Lomachenko, A. L. Bugaev, S. Bordiga, A. V. Soldatov, K. P. Lillerud and C. Lamberti, Catal. Today, 2017, 283, 89-103.

61 F. Xamena, O. Casanova, R. G. Tailleur, H. Garcia and A. Corma, J. Catal., 2008, 255, 220-227.

62 A. Corma, M. Iglesias, F. Xamena and F. Sanchez, Chem.-Eur. J., 2010, 16, 9789-9795.

63 I. Luz, F. Xamena and A. Corma, J. Catal., 2010, 276, 134-140.

64 E. Borfecchia, D. Gianolio, G. Agostini, S. Bordiga and C. Lamberti, in Metal Organic Frameworks as Heterogeneous Catalysts, ed. F. Xamena and J. Gascon, Royal Society of Chemistry, Cambridge, 2013, pp. 143-208.

65 S. Bordiga, E. Groppo, G. Agostini, J. A. van Bokhoven and C. Lamberti, Chem. Rev., 2013, 113, 1736-1850.

66 K. C. Szeto, K. P. Lillerud, M. Tilset, M. Bjorgen, C. Prestipino, A. Zecchina, C. Lamberti and S. Bordiga, J. Phys. Chem. B, 2006, 110, 21509-21520.

67 K. C. Szeto, C. Prestipino, C. Lamberti, A. Zecchina, S. Bordiga, M. Bjorgen, M. Tilset and K. P. Lillerud, Chem. Mater., 2007, 19, 211-220.

68 J. Hafizovic, M. Bjorgen, U. Olsbye, P. D. C. Dietzel, S. Bordiga, C. Prestipino, C. Lamberti and K. P. Lillerud, J. Am. Chem. Soc., 2007, 129, 3612-3620.

69 S. Chavan, F. Bonino, J. G. Vitillo, E. Groppo, C. Lamberti, P. D. C. Dietzel, A. Zecchina and S. Bordiga, Phys. Chem. Chem. Phys., 2009, 11, 9811-9822.

70 S. Bordiga, F. Bonino, K. P. Lillerud and C. Lamberti, Chem. Soc. Rev., 2010, 39, 4885-4927.

71 E. Borfecchia, S. Maurelli, D. Gianolio, E. Groppo, M. Chiesa, F. Bonino and C. Lamberti, J. Phys. Chem. C, 2012, 116, 19839-19850.

72 L. Valenzano, J. G. Vitillo, S. Chavan, B. Civalleri, F. Bonino, S. Bordiga and C. Lamberti, Catal. Today, 2012, 182, 67-79.

73 E. Borfecchia, L. Braglia, F. Bonino, S. Bordiga, S. Øien, U. Olsbye, K. P. Lillerud, J. A. van Bokhoven, K. A. Lomachenko, A. A. Guda, A. V. Soldatov and C. Lamberti, in XAFS Techniques for Catalysts, Nanomaterials, and Surfaces, ed. Y. Iwasawa, K. Asakura and M. Tada, Springer, Berlin, 2017, pp. 397-430.

74 M. Muller, S. Hermes, K. Kaehler, M. W. E. van den Berg, M. Muhler and R. A. Fischer, Chem. Mater., 2008, 20, 4576-4587.

75 E. D. Bloch, D. Britt, C. Lee, C. J. Doonan, F. J. Uribe-Romo, H. Furukawa, J. R. Long and O. M. Yaghi, J. Am. Chem. Soc., 2010, 132, 14382-14384.

76 S. Gross and M. Bauer, Adv. Funct. Mater., 2010, 20, 4026-4047.

77 T. B. Celic, M. Rangus, K. Lazar, V. Kaucic and N. Z. Logar, Angew. Chem., Int. Ed., 2012, 51, 12490-12494.

78 T. H. Zhou, Y. H. Du, A. Borgna, J. D. Hong, Y. B. Wang, J. Y. Han, W. Zhang and R. Xu, Energy Environ. Sci., 2013, 6, 3229-3234. 
79 M. Carboni, Z. K. Lin, C. W. Abney, T. Zhang and W. B. Lin, Chem.-Eur. J., 2014, 20, 14965-14970.

80 X. L. Li, Z. Y. Guo, C. X. Xiao, T. W. Goh, D. Tesfagaber and W. Y. Huang, ACS Catal., 2014, 4, 3490-3497.

81 C. X. Xiao, T. W. Goh, K. Brashler, Y. C. Pei, Z. Y. Guo and W. Y. Huang, J. Phys. Chem. B, 2014, 118, 14168-14176.

82 Z. Y. Zhang, H. Yoshikawa and K. Awaga, J. Am. Chem. Soc., 2014, 136, 1611216115.

83 D. R. Sun, F. X. Sun, X. Y. Deng and Z. H. Li, Inorg. Chem., 2015, 54, 86398643.

84 M. Du, L. Li, M. X. Li and R. Si, RSC Adv., 2016, 6, 62705-62716.

85 J. Ethiraj, F. Bonino, J. G. Vitillo, K. A. Lomachenko, C. Lamberti, H. Reinsch, K. P. Lillerud and S. Bordiga, ChemSusChem, 2016, 9, 713-719.

86 Z. G. Hu, J. J. Lin, N. Ogiwara, A. Rodriguez, Y. W. Peng, Y. X. Wang, S. Horike and D. Zhao, CrystEngComm, 2016, 18, 2803-2807.

87 A. S. Munn, F. Millange, M. Frigoli, N. Guillou, C. Falaise, V. Stevenson, C. Volkringer, T. Loiseau, G. Cibin and R. I. Walton, CrystEngComm, 2016, 18, 8108-8114.

88 N. C. Thacker, Z. K. Lin, T. Zhang, J. C. Gilhula, C. W. Abney and W. B. Lin, J. Am. Chem. Soc., 2016, 138, 3501-3509.

89 G. Wang, K. Leus, S. Couck, P. Tack, H. Depauw, Y. Y. Liu, L. Vincze, J. F. M. Denayer and P. Van der Voort, Dalton Trans., 2016, 45, 9485-9491.

90 D. Yang, S. O. Odoh, J. Borycz, T. C. Wang, O. K. Farha, J. T. Hupp, C. J. Cramer, L. Gagliardi and B. C. Gates, ACS Catal., 2016, 6, 235-247.

91 G. M. Sheldrick, Acta Crystallogr., Sect. A: Found. Adv., 2015, 71, 3-8.

92 G. M. Sheldrick, Acta Crystallogr., Sect. C: Struct. Chem., 2015, 71, 3-8.

93 O. V. Dolomanov, L. J. Bourhis, R. J. Gildea, J. A. K. Howard and H. Puschmann, J. Appl. Crystallogr., 2009, 42, 339-341.

94 C. C. Wang, Acta Crystallogr., Sect. E: Struct. Rep. Online, 2009, 65, 02081.

95 A. Schaate, P. Roy, A. Godt, J. Lippke, F. Waltz, M. Wiebcke and P. Behrens, Chem.-Eur. J., 2011, 17, 6643-6651.

96 S. Carlson, M. Clausen, L. Gridneva, B. Sommarin and C. Svensson, J. Synchrotron Radiat., 2006, 13, 359-364.

97 C. Lamberti, C. Prestipino, S. Bordiga, G. Berlier, G. Spoto, A. Zecchina, A. Laloni, F. La Manna, F. D’Anca, R. Felici, F. D’Acapito and P. Roy, Nucl. Instrum. Methods Phys. Res., Sect. B, 2003, 200, 196-201.

98 B. Ravel and M. Newville, J. Synchrotron Radiat., 2005, 12, 537-541.

99 M. Newville, J. Synchrotron Radiat., 2001, 8, 322-324.

100 S. I. Zabinsky, J. J. Rehr, A. Ankudinov, R. C. Albers and M. J. Eller, Phys. Rev. B: Condens. Matter Mater. Phys., 1995, 52, 2995-3009.

101 J. J. Rehr and R. C. Albers, Rev. Mod. Phys., 2000, 72, 621-654.

102 M. Reiher, O. Salomon and B. A. Hess, Theor. Chem. Acc., 2001, 107, 48-55.

103 C. F. Guerra, J. G. Snijders, G. te Velde and E. J. Baerends, Theor. Chem. Acc., 1998, 99, 391-403.

104 G. te Velde, F. M. Bickelhaupt, E. J. Baerends, C. F. Guerra, S. J. A. Van Gisbergen, J. G. Snijders and T. Ziegler, J. Comput. Chem., 2001, 22, 931-967.

105 M. Lersch and M. Tilset, Chem. Rev., 2005, 105, 2471-2526.

106 R. A. Periana, D. J. Taube, S. Gamble, H. Taube, T. Satoh and H. Fujii, Science, 1998, 280, 560-564. 
107 D. Wolf, Angew. Chem., Int. Ed., 1998, 37, 3351-3353.

108 R. Palkovits, M. Antonietti, P. Kuhn, A. Thomas and F. Schüth, Angew. Chem., Int. Ed., 2009, 48, 6909-6912.

109 R. Palkovits, C. von Malotki, M. Baumgarten, K. Mullen, C. Baltes, M. Antonietti, P. Kuhn, J. Weber, A. Thomas and F. Schüth, ChemSusChem, 2010, 3, 277-282.

110 M. Soorholtz, R. J. White, T. Zimmermann, M. M. Titirici, M. Antonietti, R. Palkovits and F. Schüth, Chem. Commun., 2013, 49, 240-242.

111 G. W. Stinton and J. S. O. Evans, J. Appl. Crystallogr., 2007, 40, 87-95.

112 G. Agostini, C. Lamberti, L. Palin, M. Milanesio, N. Danilina, B. Xu, M. Janousch and J. A. van Bokhoven, J. Am. Chem. Soc., 2010, 132, 667-678.

113 G. Bunker, Introduction to XAFS A Practical Guide to X-ray Absorption Fine Structure Spectroscopy, Cambridge University Press, Cambridge, 2010.

114 M. D. Hall, G. J. Foran, M. Zhang, P. J. Beale and T. W. Hambley, J. Am. Chem. Soc., 2003, 125, 7524-7525.

115 H. Yoshida, S. Nonoyama, Y. Yazawa and T. Hattori, Phys. Scr., 2005, 115, 813-815.

116 E. Borfecchia, S. Oien, S. Svelle, L. Mino, L. Braglia, G. Agostini, E. Gallo, K. A. Lomachenko, S. Bordiga, A. A. Guda, M. A. Soldatov, A. V. Soldatov, U. Olsbye, K. P. Lillerud and C. Lamberti, J. Phys. Conf. Ser., 2016, 712, 012125.

117 S. A. Guda, A. A. Guda, M. A. Soldatov, K. A. Lomachenko, A. L. Bugaev, C. Lamberti, W. Gawelda, C. Bressler, G. Smolentsev, A. V. Soldatov and Y. Joly, J. Chem. Theory Comput., 2015, 11, 4512-4521.

118 G. Berlier, G. Spoto, S. Bordiga, G. Ricchiardi, P. Fisicaro, A. Zecchina, I. Rossetti, E. Selli, L. Forni, E. Giamello and C. Lamberti, J. Catal., 2002, 208, 64-82.

119 G. Berlier, G. Spoto, P. Fisicaro, S. Bordiga, A. Zecchina, E. Giamello and C. Lamberti, Microchem. J., 2002, 71, 101-116.

120 A. Zecchina, M. Rivallan, G. Berlier, C. Lamberti and G. Ricchiardi, Phys. Chem. Chem. Phys., 2007, 9, 3483-3499.

121 A. I. Frenkel, J. Synchrotron Radiat., 1999, 6, 293-295.

122 A. I. Frenkel, C. W. Hills and R. G. Nuzzo, J. Phys. Chem. B, 2001, 105, 1268912703.

123 D. Glasner and A. I. Frenkel, in X-Ray Absorption Fine Structure-XAFS13, ed. B. Hedman and P. Painetta, American Institute of Physics, Melville, 2007, vol. 882, pp. 746-748.

124 G. Agostini, R. Pellegrini, G. Leofanti, L. Bertinetti, S. Bertarione, E. Groppo, A. Zecchina and C. Lamberti, J. Phys. Chem. C, 2009, 113, 10485-10492.

125 G. Agostini, A. Piovano, L. Bertinetti, R. Pellegrini, G. Leofanti, E. Groppo and C. Lamberti, J. Phys. Chem. C, 2014, 118, 4085-4094.

126 B. Abecassis, F. Testard, O. Spalla and P. Barboux, Nano Lett., 2007, 7, 17231727.

127 J. Polte, T. T. Ahner, F. Delissen, S. Sokolov, F. Emmerling, A. F. Thunemann and R. Kraehnert, J. Am. Chem. Soc., 2010, 132, 1296-1301.

128 E. Groppo, G. Agostini, A. Piovano, N. B. Muddada, G. Leofanti, R. Pellegrini, G. Portale, A. Longo and C. Lamberti, J. Catal., 2012, 287, 44-54.

129 G. Agostini, C. Lamberti, R. Pellegrini, G. Leofanti, F. Giannici, A. Longo and E. Groppo, ACS Catal., 2014, 4, 187-194. 
130 E. Groppo, G. Agostini, E. Borfecchia, L. Wei, F. Giannici, G. Portale, A. Longo and C. Lamberti, J. Phys. Chem. C, 2014, 118, 8406-8415.

131 N. T. K. Thanh, N. Maclean and S. Mahiddine, Chem. Rev., 2014, 114, 76107630.

132 E. Groppo, G. Agostini, E. Borfecchia, A. Lazzarini, W. Liu, C. Lamberti, F. Giannici, G. Portale and A. Longo, ChemCatChem, 2015, 7, 2188-2195.

133 P. Kluth, B. Johannessen, G. J. Foran, D. J. Cookson, S. M. Kluth and M. C. Ridgway, Phys. Rev. B: Condens. Matter Mater. Phys., 2006, 74, 9.

134 L. Guczi, A. Beck, A. Horvath, Z. Koppany, G. Stefler, K. Frey, I. Sajo, O. Geszti, D. Bazin and J. Lynch, J. Mol. Catal. A: Chem., 2003, 204, 545-552.

135 A. Witkowska, A. Di Cicco and E. Principi, Phys. Rev. B: Condens. Matter Mater. Phys., 2007, 76, 12.

136 G. Turnes Palomino, P. Fisicaro, S. Bordiga, A. Zecchina, E. Giamello and C. Lamberti, J. Phys. Chem. B, 2000, 104, 4064-4073.

137 F. X. Llabrés i Xamena, P. Fisicaro, G. Berlier, A. Zecchina, G. Turnes Palomino, C. Prestipino, S. Bordiga, E. Giamello and C. Lamberti, J. Phys. Chem. B, 2003, 107, 7036-7044.

138 M. Benfatto, P. D’Angelo, S. Della Longa and N. V. Pavel, Phys. Rev. B: Condens. Matter Mater. Phys., 2002, 65, 174205.

139 E. M. Alayon, M. Nachtegaal, M. Ranocchiari and J. A. van Bokhoven, Chem. Commun., 2012, 48, 404-406.

140 F. Giordanino, E. Borfecchia, K. A. Lomachenko, A. Lazzarini, G. Agostini, E. Gallo, A. V. Soldatov, P. Beato, S. Bordiga and C. Lamberti, J. Phys. Chem. Lett., 2014, 5, 1552-1559.

141 E. Borfecchia, K. A. Lomachenko, F. Giordanino, H. Falsig, P. Beato, A. V. Soldatov, S. Bordiga and C. Lamberti, Chem. Sci., 2015, 6, 548-563.

142 C. Lamberti, C. Prestipino, F. Bonino, L. Capello, S. Bordiga, G. Spoto, A. Zecchina, S. D. Moreno, B. Cremaschi, M. Garilli, A. Marsella, D. Carmello, S. Vidotto and G. Leofanti, Angew. Chem., Int. Ed., 2002, 41, 2341-2344.

143 N. B. Muddada, U. Olsbye, L. Caccialupi, F. Cavani, G. Leofanti, D. Gianolio, S. Bordiga and C. Lamberti, Phys. Chem. Chem. Phys., 2010, 12, 5605-5618.

144 L. S. Kau, D. J. Spirasolomon, J. E. Pennerhahn, K. O. Hodgson and E. I. Solomon, J. Am. Chem. Soc., 1987, 109, 6433-6442.

145 M. H. Groothaert, J. A. van Bokhoven, A. A. Battiston, B. M. Weckhuysen and R. A. Schoonheydt, J. Am. Chem. Soc., 2003, 125, 7629-7640.

146 G. Kresse and J. Furthmuller, Comput. Mater. Sci., 1996, 6, 15-50.

147 G. Kresse and J. Furthmuller, Phys. Rev. B: Condens. Matter Mater. Phys., 1996, 54, 11169-11186.

148 L. Braglia, E. Borfecchia, K. A. Lomachenko, S. Oien, K. P. Lillerud and C. Lamberti, J. Phys. Conf. Ser., 2016, 712, 012053.

149 M. Gonzalez, J. Oktawiec and J. R. Long, Faraday Discuss., 2017, DOI: 10.1039/ c7fd00061h.

150 M. I. Gonzalez, E. D. Bloch, J. A. Mason, S. J. Teat and J. R. Long, Inorg. Chem., 2015, 54, 2995-3005.

151 R. Y. Huang, Y. Peng, C. Wang, Z. Shi and W. B. Lin, Eur. J. Inorg. Chem., 2016, 4358-4362.

152 N. C. Thacker, P. Ji, Z. Lin, A. Urban and W. Lin, Faraday Discuss., 2017, DOI: 10.1039/c7fd00030h. 